\title{
ACTIVIDADES DE LA ENAP (CFYPF)
}

1. Cursos celebrados durante el mes de enero de 1967

\section{1,1 VI CuRso de Formación DE TÉCNICOS DE ADMINISTRACIÓN CIVIL}

En el mes de enero ha continuado este VI Curso, del que se han dado noticias en distintos números de esta Revista.

- Durante el citado mes es preciso destacar la iniciación de un ciclo de estructura económica que se desarrollará durante los meses de enero, febrero y marzo. Dentro de este ciclo se han examinado hasta ahora los temas de "La balanza de pagos)», (cLa lucha antimonopolio», "EI sistema bancario» y "Los transportes». También es de destacar la conferencia pronunciada por don José Rodríguez Soler, vicedecano de los letrados consistoriales del Ayuntamiento de Madrid, y que versó sobre el tema «Problemas jurídico-administrativos del Municipio de Madrid».

Dentro del programa de visita a distintos organismos de la Administración y empresas privadas, se realizó una a la Jefatura Central de Tráfico.

\section{1,2 I CuRSO ESPECIAL DE MECANIZACIÓN ADMINISTRATIVA - El día 23 de enero dió comienzo este primer curso, que se desarrollará}


durante dos semanas, con un total de 40 horas lectivas. A este curso asisten 20 funcionarios procedentes de distintos ministerios. El programa incluye, fundamentalmente, las siguientes materias: Concepto y alcance de la mecanización administrativa; clases de utensilios y máquinas; máquinas de direcciones (método operativo, elementos y aplicaciones prácticas); máquinas aplicadas a la contabilidad (variedades, método operativo y trabajos realizados con sus distintas clases) ; máquinas especiales (variedades, métodos operativo y aplicaciones de las distintas clases); máquinas para el tratamiento conjunto de la información (sus clases, método operativo, elementos del equipo, aplicaciones); introducción al tratamiento integrado de la información.

\section{1,3 I CURSO ESPECIAL DE NORMAS LABORALES : REGLAMENTACIÓN DE TRABAJO, CONVENIOS COLECTIVOS Y REGLAMENTACIÓN DE EMPRESAS}

Como ya se indicó en el número de noviembre de esta Revista, el primer Curso especial de normas laborales se programó para desarrollarse del 23 de enero al 3 de febrero de 1967. A este primer. curso asisten 18 funcionarios. Las materias objeto del curso son:

Fuentes del Derecho del trabajo; Poderes sociales con facultad normativa laboral creadora; Normas laborales; Normas constitucionales; La ley en el ámbito laboral ; El principio de legalidad en la esfera laboral; Los reglamentos del trabajo; La legislación de urgencia (decretos-leyes); La legislación delegada (de- cretos-legislativos); La costumbre laboral; Principios generales del Derecho y principios especificos del Derecho laboral; El principio «pro operario» y sus manifestaciones; La norma más favorable y la condición más beneficiosa; Normas internacionales; La jurisprudencia laboral; El Derecho común como Derecho supletorio y la doctrina cientifica; Reglamentaciones de trabajo; Convenios colectivos, normas de obligado cumplimiento; Reglamentos de régimen interior; La norma laboral en el espacio; La norma laboral en el tiempo; El contrato de trabajo como norma; la jerarquia de las normas laborales.

2. Cursos de formación para funcionarios del Cuerpo-General Administrativo

\section{2,1 VII CURSO DE FORMacióN}

El pasado día 9 de enero comenzó este VII Curso, al que asisten 26 funcionarios. Se desarrolla en jornada de mañana, durante todos los días de la semana, excepto los sábados. Su programa es análogo al de anteriores cursos celebrados.

3. Cursos de formación para auxiliares de Administración Civil

\section{3,1 VII CURSO DE FORMACIÓN (PRIMER GRUPO)}

El día 16 de enero dió comienzo el primer grupo (200 aspirantes) del Curso de Formación para los seleccionados en las pruebas correspondientes del turno restringido, para ingreso en el Cuerpo General Auxi- 
liar de la Administración Civil del Estado.

El curso se desarrollará durante las tardes, y tendrá una duración de cuatro semanas. Las materias incluidas en el programa son las siguientes: Organización del Estado; Régimen de la Función pública; Procedimiento administrativo; Relaciones humanas; Organización y simplificación del trabajo; Clasificación, impresos, archivos, fichas y ficheros; Máquinas de oficinas y Materias especiales relativas a la organización y servicios de los ministerios.

El curso finalizará con una prueba de cada una de las materias indicadas.

4. Cursos que se celebrarán en los meses de abril y mayo

\section{4,1 Cursos generales de \\ PERFECCIONAMIENTO PARA TÉCNICOS DE ADMINISTTRaCión Crvil $Y$ OTROS FUNCIONARIOS CON TITULACIÓN ACADÉMICA SUPERIOR}

El XXXI Curso general de Perfeccionamiento está programado para realizarse del 10 al 21 de abril, en régimen de Jornada completa, de las nueve a las diecisiete horas, durante todos los dias laborables de la semana, excepto sábados. Las materias que incluirá el programa de este curso serán las mismas que las de cursos anteriores, es decir, Organización y funciones directivas, Métodos de trabajo, Administráción de Personal, Administración financiera, Sicología administrativa y Procedimiento administrativo. Su duración será de 50 horas lectivas.

\section{4,2 Cursos generales}

DE PERFECCIONAMIENTO

PARA FUNCIONARIOS COMPRENDIDOS EN EL ARTICULO PRIMERO

DEL DECRETO-LEY 10/1964,

DE 3 DE JULIO

Del 17 al 28 de abril está programado la realización del VI Curso para los funcionarios indicados. Se celebrará en régimen de fornada completa, de las nueve a las diecisiete horas, durante todos los días laborables de la semana, excepto sábados. E1 programa de este curso es análogo a! anteriormente citado.

\section{4,3 Cursos especiales}

DE PERFECCIONAMIENTO

PARA TÉCNICOS

DE AdMinistración Civil

$Y$ OTROS FUNCIONARIOS

CON TITULACIÓN ACADEMICA SUPERIOR

4,301 El régimen general de la Seguridad Social. (40 horas lectivas)

Este curso se celebrará del 24 de abril al 29 de mayo, en régimen de jornada de mañana, de las nueve a las trece $y$ treinta horas, durante las lunes y miércoles de cada semana.

\section{4,302 Normas laborales: Reglamen- tación de trabajo, convenios colectivos y reglamentación de empresas. (40 horas lectivas)}

Este curso, que será el segundo de los programados bajo este título, se celebrará del 25 de abril al 6 de mayo, en régimen de jornada de maña- 
na, de las nueve a las trece y treinta horas, durante los martes $\mathbf{y}$ viernes de cada semana.

\section{4,303 Administración de Personal. (60 horas lectivas)}

Este curso será el tercero de los programados sobre la materia, y se desarrollará del 10 al 28 de abril, en régimen de jornada de mañana, de las nueve a las trece y treinta horas, durante todos los dias laborables de la semana, excepto sábados.

\section{4,304 Administración financiera. (40 horas lectivas)}

Este curso también será el tercero de los programados, y se desarrollará del 17 al 28 de abril, en régimen de jornada de mañana, de las nueve a las trece y treinta horas, durante todos los días laborables de la semana, excepto sábados.

\section{4,305 Coste y rendimiento de los servicios piblicos. $(40$ horas lectivas) .}

Se ha programado un primer curso sobre esta materia, que se celebrará del 17 al 28 de abril, en jornada de tarde, de las dieciséis a las veinte y treinta horas, durante todos los dias laborables de la semana, excepto sábados.

\section{4,306 Mecanización administrativa (40 horas lectivas)}

E1 II Curso de mecanización administrativa está programado del.17 al
28 de abril, en régimen de jornada de tarde, de las dieciséis a las veinte y treinta horas.

4,307 I Curso de actualización de Organización y Métodos para diplomados en la especialiaad

Se ha programado un I Curso de actualización de Organización y Métodos, al que podrán concurrir los diplomados por convalidación, en aplicación del decreto de 28 de diciembre de $1960, y$ los participantes en el I Curso de Organización y Métodos que fué convocado en 1962. La duración de este curso será de 160 horas lectivas, y se desarrollará en rógimen de jornada de mañana, de las nueve a las trece y treinta horas, durante todos los días laborables sucesivos, excepto sábados. Dará comienzo el día 24 de abril, y finalizará el 23 de junio de 1967.

\section{4,308 Ciclo de éstudios sóciales}

Con este titulo se han programado una serie de cursos, entre los que cabe destacar los siguientes:

- Estadística social. Su duración será de 60 horas lectivas, y se programarán dos cursos: E1 primero, del 10 al 21 de abril, $y$ el segundo, del 24 de abril al 6 de mayo. Se desarrollarán en régimen de jornada de tarde, de las dieciséis a las veinte $\mathrm{y}$ treinta horas.

- Métodos de investigación social. La duración de este curso será 
de 40 horas lectivas, y se desarrollará también en régimen de jornada de tarde. Se han programado dos cursos: el primero, del 10 al 21 de abril, y el segundo, del 24 de abril al 6 de mayo.

- Introducción de la sicología social. (40 horas lectivas.)

Fste curso se desarrollará del 8 al 19 de mayo, en régimen de jornada de tarde, de las dieciséis a las veinte y treinta horas, durante todos los días laborables de la semana, excepto sábados.

4,309 Técnicas de Administración de la educación. (100 horas lectivas)

El II Curso de Técnicas de Administración de la educación se desarrollará del 2 de mayo al 2 de junio, en régimen de jornada de tarde, de las dieciséis a las veinte y treinta horas. El programa de este II Curso será análogo al del primero celebrado.

\section{4,310 Servicios administrativos de la agricultura. (60 horas lectivas)}

Este I Curso se desarrollará del 10 a? 28 de abril, en régimen de jornada de tarde, de las dieciséis a las veinte y treinta horas, durante todos los dias laborables de la semana, excepto sábados.

\section{Solicitudes para participar en estos cursos}

Las solicitudes para participar en los cursos generales y especiales de perfeccionamiento indicados se ajustarán a las normas que la convocatoria establezca y que oportunamente se hará pública en el Boletín Oficial del Estado. En dicha convocatoria figurarán también los programas respectivos de cada curso.

Clave para la calificación del cuestionario

Proposiciones ciertas: 2, 4, 6, 7, 8, 11, 12, 14, 15, 17, 20, 21, 22, 24, 27, 28, 29. Proposiciones falsas: $1,3,5,9,10,13,16,18,19,23,25,26,30$. 
DA-1967, núm. 109. ACTIVIDADES DE LA ENAP

DA-1967, núm. 109. ACTIVIDAD̀ES DE LA ENAP 
DA-1967, núm. 109. ACTIVIDADES DE LA ENAP

DA-1967, núm. 109. ACTIVIDADES DE LA ENAP 
DA-1967, núm. 109. ACTIVIDADES DE LA ENAP

DA-1967, núm. 109. ACTIVIDADES DE LA ENAP 